\title{
CIENTO CUATRO AÑOS DE ANTROPOLOGÍA MEXICANA
}

\author{
One hundred and four years of Mexican Anthropology
}

\section{LUIS VÁZQUEZ LEÓN *}

\section{Resumen}

Luego de un siglo de existencia institucional y profesional la antropología mexicana ha constituido una treintena de escuelas, facultades, institutos, colegios y centros de investigación, todos los cuales ofrecen estudios de licenciatura, maestría y doctorado. En apariencia, es una disciplina consolidada. Es preocupante, sin embargo, que mientras prevalece el desempleo de los jóvenes profesionales, la política científica haya tenido el efecto de crear una élite menos interesada en los "grandes problemas nacionales" que en reproducir más profesionales con futuro incierto. La supuesta "comunidad antropológica" está escindida en una antropología académica y una antropología gubernamental, y los esfuerzos por reunirlas son aún incipientes. La élite está preocupada también por su visibilidad internacional, ubicando a la antropología gubernamental (que en su época de oro dio fama internacional a la antropología mexicana) en un nivel inferior, pese a su producción constante de estudios, los que también contribuyen al desarrollo disciplinar.

Palabras Clave: Instituciones antropológicas, Mundialización, Ciencia normal, Conflictos.

\section{Abstract}

After a century of institutional and professional existence, Mexican anthropology is formed by thirty schools, colleges, institutes, and research centers, all of which offer undergraduate, master's and doctoral degrees. Apparently, it is a consolidated discipline. It is disturbing, however, that while unemployment prevails among young professionals, science policies have had the effect of creating an elite less interested in the "larger national issues", than in the production of professionals with an uncertain future. The alleged "anthropological community" is divided into an academic anthropology and a governmental anthropology and the efforts to bring them together are still incipient. The elite is concerned about its international visibility, placing governmental anthropology (which in its golden age gave international fame to Mexican anthropology) at a lower level, despite its constant production of studies, which also contribute to the development of the discipline.

Key words: Anthropological institutions, Globalization, Normal science, Conflict

\footnotetext{
* Antropólogo. Doctor en Antropología Social. Investigador Centro de Investigaciones y Estudios Superiores en Antropología Social - CIESAS de occidente. Correo electrónico: Ivazquez@ciesas.edu.mx, Ivazquez@ciesasoccidente. edu. $\mathrm{mx}$
} 


\section{Introducción}

Si convenimos en considerar al año de 1910 como el inicio de la antropología profesionalizada en México -dado que se funda entonces la Escuela Internacional de Arqueología y Etnología Americanas-, entonces pretender ofrecer una visión de conjunto de esta ciencia social implica referirse a más de un siglo de prácticas e ideas de diversa índole. Un periodo en el que pueden haber fundaciones de instituciones como rupturas, escándalos y cotidianeidad y, producción de obras claves, al igual que una inmensa cantidad de literatura que realmente hace normal la actividad toda y aún la constitución de unas comunidades virtuales (asociaciones, congresos, redes, etc.), que se sobreponen a los conflictos más profundos. En lo que sigue no intento hacer un recuento histórico pormenorizado de un siglo de avances y retrocesos, sino más bien reflexionar, tal como lo hemos venido haciendo varios autores (Vázquez, 2002; Giglia, Garma \& de Teresa, 2007; Krotz \& de Teresa, 2012), sobre lo que ha sido, sobre lo que es y sobre lo que será la antropología tras un siglo de existencia. La profesionalización de esta ciencia social coincide en sus orígenes, con una escuela que desapareció -no obstante ser un esfuerzo incipiente por internacionalizarse- y que luego de este esfuerzo fallido, fue relevada por una escuela de orientación nacional existente hasta la fecha. Esto, sumado al hecho que posteriormente emergieran de forma casi simultánea una treintena de nuevas escuelas, institutos, colegios y un centro de investigaciones, haría pensar, de forma complaciente, en que el futuro de esta disciplina está plenamente asegurado. Deberíamos celebrarlo. Pero antes de instalarnos en un área de seguridad y confort ontológicos, habría que recordar que venimos de un fracaso inicial y, que la mayor institución antropológica en México, el Instituto Nacional de Antropología e Historia (INAH), con 950 investigadores en su planta, continuamente vive dudas sobre su persistencia y, que ellos no son los únicos. En los momentos en que escribo, el Sistema Nacional de Investigadores (SNI), que es el sostén de toda la élite científica mexicana, está siendo revisado por el Consejo Nacional de Ciencia y Tecnología (CONACYT) a raíz de la creciente percepción de la ineficacia del juicio o evaluación de pares sobre el que descansa su membresía. Algunas medidas correctivas ya han sido tomadas, pero cabe la pregunta si habrá más en el futuro. Puede ser entonces que haya llegado el momento de hacer un balance provisional de ese siglo de antropología si vislumbramos una renovación relevante. La orientación nacional o internacional es una de las disyuntivas básicas, pero hay otras pendientes como la orientación gubernamental o académica, o aquélla otra de sobrevalorarnos de modo comunitario cuando la exigencia puede estar allá afuera de la profesión.

\section{La antropología gubernamental: ¿sobreseída por la académica?}

En mi vida profesional he pasado la mitad en una y otra forma que ha tenido de constituirse la antropología mexicana, y veo entonces tanto problemas como aciertos en ambas, y por ende no sobrepondría a una sobre la otra. De hecho, pienso que ambas son necesarias y se requieren entre sí. Numéricamente las diferencias son evidentes y hasta contradictorias frente a mi pregunta. Mientras el Instituto Nacional de Antropología e Historia (INAH) reúne a 950 investigadores (arqueólogos, historiadores, etnohistoriadores, 
lingüistas, antropólogos físicos, etnólogos y antropólogos sociales), a los que es preciso agregar 250 investigadores más "no basificados" (o sea, aún sin contratación permanente), el Centro de Investigaciones y Estudios Superiores en Antropología Social (CIESAS) reúne solo a 148 investigadores (antropólogos sociales, historiadores, lingüistas y sociólogos). La planta de ambas instituciones -emblemáticas de la antropología gubernamental y de la antropología académica, respectivamente- indica que no crecen al mismo ritmo, ni hay la misma demanda profesional en cada una. De hecho, una requiere personal muy calificado, mientras la otra prefiere al personal especializado, de calificación variable.

Para empezar, entonces, hay que desdibujar con firmeza la concepción de que una y otra antropologías son antagónicas. Difieren sí, pero poco a poco se van asemejando. El origen de esta percepción antagónica son dos conflictos internos que provienen de dos rupturas profesionales, una ocurrida en 1943 y otra en 1968. En ambas, grupos de antropólogos innovadores -muchos de los cuales optaron por llamarse antropólogos sociales críticos, aunque en 1948 hubo dos arqueólogos destacados también- entraron en conflicto por adoptar visiones distintas a las del pensamiento dominante, prohijado por el entonces director vitalicio del INAH y quién introdujo un lenguaje denigratorio hacia sus opositores, pero también con otros de sus colegas cercanos. Es muy posible que de este estilo autoritario venga la práctica del arqueólogo enemigo, pero asimismo del colega enemigo, al que hay que ignorar, ofender, y sobre todo, nunca leer, lo que incluye la práctica de nunca citar en los textos académicos, es decir, no reconocerle ningún mérito. Esta práctica nulificadora existe tanto en las instituciones gubernamentales como en las académicas, por las cuales me refiero no solo al CIESAS, sino a las escuelas universitarias esparcidas por todo el territorio nacional.

Los dos conflictos citados indujeron a la postre a crear nuevas instituciones y escuelas, lo que es la parte más positiva de su desenlace. Del INAH se desprendió el Centro de Investigaciones Superiores del INAH (CISINAH) en 1973 y de éste devino el CIESAS, en 1980, no sin dejar de mediar un conflicto personal entre sus primeros dos directores (Téllez-Girón \& Vázquez, 2013). Dicho de otra manera, de la antropología gubernamental surgió un segmento importante de la antropología académica de hoy. Asimismo, a las escuelas iniciales ubicadas en varios estados (Yucatán y Veracruz, más tarde Puebla y Chiapas) sucedieron otras escuelas mucho menos parecidas a la Escuela Nacional de Antropología e Historia-ENAH (con excepción de la ENAH Chihuahua, que de todos modos se ocupaba al inicio solo de la antropología social aplicada), existente desde 1939, aunque ella misma tuvo una breve vida académica dentro del Instituto Politécnico Nacional. Por mucho tiempo la antropología de la ENAH y la demanda institucional del INAH se confundieron, incluso cuando se creó el Instituto Nacional Indigenista en 1949, que de todos modos requirió de un perfil aplicado y una instrucción etnológica formativa $y$, que terminó transformada en un campo de la antropología social. La oferta académica creció muy lentamente en la Universidad Nacional Autónoma de México (UNAM) y el verdadero cambio vino hacia finales del siglo XX, en que los antropólogos se abrieron paso en las universidades públicas estatales, así como en cuatro colegios con influencia de El Colegio de México (COLMEX). Muchas historias pioneras se cuentan al respecto, incluso sobre el fracaso del Colegio del Bajío. 
En cierto modo, se podría decir que ambas maneras de practicar la antropología se han ido acercando, copiándose estilos. Muchos de los investigadores del INAH, aún los más ligados a la administración patrimonial (zonas arqueológicas, museos y bienes históricos) han aprendido a gestionar recursos de CONACYT, al tiempo que CIESAS se convirtió en Centro Público de Investigación, plenamente integrado a ese organismo central de la ciencia y la tecnología. El propio INAH se distanció de la Secretaría de Educación Pública (SEP) y, se subordinó al Consejo Nacional para la Cultura y las Artes (CONACULTA). De modo que la línea de demarcación de lo gubernamental y lo académico se atenúo y, quizás solo los colegios retengan cierta autonomía heredada del decreto de creación del COLMEX, aunque de todos modos deben negociar recursos dentro de los centros públicos del sector de ciencia y tecnología. Pero aun así, solo en el Colegio de Michoacán he escuchado una declaración pública de defensa de su legado humanista a pesar de las políticas científicas, lo que no es claro en CIESAS, el que ha interiorizado sin chistar las cambiantes exigencias de CONACYT. Es cierto que el aparato burocrático del INAH es impresionante: su sola función ocupaba varios edificios. No obstante, se mueve. En mucho ese aparato está justificado por la masa cuantiosa de bienes llamados "patrimonio cultural" y que debe administrar por ley. También lo es que esa burocracia no entiende del todo las exigencias cotidianas de la investigación, sobre todo la que se rige por valores más académicos que aplicados, como ocurre en sus dos escuelas (ENAH y la Escuela de Antropología e Historia del Norte de México, antes ENAH Chihuahua) y en varios de sus departamentos de investigación, que funcionan con cierta autonomía relativa.
¿Qué ocurre del otro lado de la moneda? Parece que algo parecido. En CIESAS su burocracia ya tiene su edificio propio. Al respecto, no hace mucho Krotz y de Teresa (2012 y 2012a) publicaron un par de volúmenes que abiertamente desean ser la continuación de los quince volúmenes editados por García Mora (1987-1988), y que en su momento fueron todo un elogio, monumental en sí mismo, a la antropología hecha por y desde el INAH. Por el contrario, los dos libros citados en vez de avocarse a La antropología en México -título general de los quince volúmenes-, se vuelven sobre sí mismos para abordar una Antropología de la antropología mexicana, pues ambos se ocupan más bien de las instituciones y programas educativos existentes en la actualidad. En ellos reaparecen la ENAH y la ENAH Chihuahua, pero su interés se centra en las universidades públicas y, algo en verdad novedoso, en el programa formativo de la Universidad Iberoamericana, de tipo privado y orientación jesuita.

Si uno lee las historias institucionales reunidas por Krotz y de Teresa, se percata del hecho que la antropología académica hecha dentro de la universidad pública sufre también del burocratismo universitario, que en los estados del país puede ser funesto pues agrega la complicación asidua de una burocracia no pocas veces subordinada a los gobiernos estatales. Por supuesto que no es el único problema; los mismos profesores generan sus propios diferendos y llegan a divergencias casi rituales, como ocurre en la Benemérita Universidad Autónoma de Puebla, donde hay dos maestrías de antropología paralelas y en competencia de recursos, correspondientes a un instituto y a un colegio de licenciatura. No obstante, lo que sí sorprende del reporte de Pérez Lizaur y Arce Cortés (2012a:431-523) sobre la Universidad 
Iberoamericana Ciudad de México (UIA) es que trabajar bajo criterios empresariales no es el paraíso de la privatización. Incluso, dentro de la Iberoamericana se cerró una licenciatura en antropología social por resultar poco redituable. El mismo criterio llevó al cierre de la licenciatura en la Universidad Autónoma de Guadalajara (UAG), y hoy solo subsiste en la Universidad de Guadalajara (UdG), que es, por lo demás, la única licenciatura pública que se negó a participar en el proyecto AdelA (Antropología de la Antropología) que dio lugar a los dos volúmenes auspiciados por la Red de Mexicana de Instituciones de Formación de Antropólogos que estoy comentando. Más aún, la UdG se mantiene reacia a ingresar a la Red. Lo que se hace en esa licenciatura es competencia exclusiva de su burocracia de profesores y de su peculiar estructura piramidal.

Aunque en el CIESAS hay una tradición retórica de informalidad que raya en el dejar hacer y dejar pasar -lo que contrasta con el excesivo peso reglamentario del INAH-, pero que en sus orígenes pretendía mantener una burocracia reducida al mínimo posible, con el tiempo la administración de proyectos ha resultado tan cuantiosa que ha obligado a un subrepticio crecimiento del aparato administrativo y su funcionamiento casi autónomo. Es muy extraño que su Comité de Ética sea una extensión del funcionariado de la institución, cuando debería ser un organismo por entero autónomo. Algo similar ocurre con su sindicato, cosa que la burocracia del INAH no puede hacer hasta la fecha con el suyo. Por su parte, la gestión de recursos externos no presupuestados ha generado preocupación dentro de CONACYT por el crecimiento que provoca de la consultoría y sus obligaciones primarias con sus clientes, en vez de la institución.
A este fenómeno suele llamársele "antropología aplicada", pero no tiene nada en común con ella: éste es un conocimiento especializado que rara vez se ocupa de intervenir, solo en recomendar. Este crecimiento es estimulado por varios factores actuantes: la entrada de overheads a la institución, el responder a una demanda por las evaluaciones de programas sociales y la propia conveniencia pecuniaria de los investigadores, casi todos de muy alto nivel de capacitación.

En otros segmentos de la antropología académica, ha aparecido una práctica análoga para remediar la falta de empleo dentro de la academia. Es muy claro que muchos egresados no encontrarán lugar en ella. Se habla entonces de "prácticas profesionales diversas", sea como consultores o como peritos. El último Boletín del Colegio de Etnólogos y Antropólogos Sociales, AC (2013; también Escalante 2002) está dedicado a ello, pero recuerdo encuentros estudiantiles similares en la Universidad Autónoma Metropolitana. Asimismo, en la Red Mexicana de Instituciones de Formación de Antropólogos (Red-MIFA) ha habido discusiones en torno a los escasos mercados laborales existentes. Si esto ocurre dentro de las escuelas de reciente creación, la profesión toda debería preguntarse sobre su inserción en la esfera pública y si en este terreno, antropólogos gubernamentales y académicos mejor deberían estar unidos. Aparte de ser ya un interés común de supervivencia, en el INAH buena parte de sus arqueólogos hacen una especie de intervención aplicada en los sitios que trabajan, lo que ha inducido a un cambio de la mentalidad patrimonialista a una más preocupada por involucrar a las localidades, comunidades y municipios, al punto que la gestoría se ha venido a agregar a sus exigencias profesionales. 
No obstante y, a diferencia de los demás, han constituido una Red Mexicana de Arqueología que los articula y da un sentido más y más académico a su trabajo, aunque siga concentrado en el INAH y algunas universidades (México y San Luis Potosí) y, un colegio (de Michoacán). La propia revista Arqueología Mexicana posee una peculiaridad digna de destacarse: podrá no ser una revista del todo academicista, pero a cambio comunica a la arqueología con un público muy amplio de lectores (la revista se vende en muchos quioscos), lo que los mantiene presentes en la esfera pública. No se puede decir lo mismo de otras revistas, solo consultadas por los mismos especialistas.

Por último, están los programas de posgrado. Estos se han generalizado en universidades, colegios, institutos, escuelas y CIESAS estimula que cada una de sus sedes tenga una maestría y, de ser posible, un doctorado. Se puede discutir la calidad de cada programa, pero en mucho depende de las exigencias de evaluación del CONACYT, pues todos apuntan a conseguir reconocimientos $y$, con ellos becas estudiantiles y otros emolumentos, si el programa es de "nivel internacional". En esa tarea el personal muy calificado del CIESAS resulta descollante, pues todos desean cubrir los requisitos de la membresía en el SNI con cursos, tesis dirigidas y asesorías. Está práctica es ampliamente compartida por todos sin excepción. EI INAH, a través de sus escuelas (ENAH y Escuela de Antropología e Historia del Norte de MéxicoEAHNM) actúa de la misma manera y, el personal adscrito a muchos más planteles, se ha ido capacitando a ojos vistas, consiguiendo doctorados e ingreso al SNI. Podemos pues hablar de un efecto uniformizador.

\section{¿Antropología nacional vs. Antropología mundial?}

Desde la publicación del libro World Anthropologies, editado por Gustavo Lins Ribeiro y Arturo Escobar (2006), se ha propagado la idea de que la antropología nacional se hace metropolitana o perece, ahogada bajo el auge de la globalización en vigor. Algo así como si la antropología fuera una mercancía de exportación, una cosificación innecesaria (hablamos de conocimiento) pero cara a la élite antropológica. Nada así ha ocurrido desde entonces, aunque es característico de la elite el moverse en redes internacionales de investigadores, si no es que haber hecho estudios de posgrado en las antropologías de orientación mundial. En contadas excepciones, sin embargo, estos estudiosos han emprendido trabajos de campo de larga duración en otras latitudes y aplicado métodos comparativos de algún tipo. Eso sí, hay contados casos de investigadores mexicanos que se han colocado en Brasil, Chile y Estados Unidos.

Al principio de este artículo mencioné de pasada el fracaso de la Escuela Internacional de Arqueología y Etnología Americanas (1910-1935), seguida de la fundación de la ENAH, que hasta ahora persiste (Rutsch, 2007; Villalobos \& Coronado, 2003). Solo decirlo, provoca la idea equivocada de que sus orientaciones eran en principio excluyentes. La orientación diferente de ambas fue real, pero ello no impidió imbricaciones entre ambas orientaciones a través de las redes maestrosalumnos. Las primeras generaciones de la ENAH se acostumbraron pronto a un profesorado extranjero, que incluso atrajo los primeros egresados hacia sus proyectos (Faulhaber, 2011). Esto hubiera continuado de no ocurrir el conflicto con los 
exiliados españoles, que se derivó en una xenofobia nacionalista que se siguió alimentando por razones de competencia profesional (Juan Comas iba a la dirección de la ENAH y Ángel Palerm a la dirección del Museo Nacional de Antropología). Finalmente, en 1968, las cosas se llevaron al extremo intolerante de expulsar a excelentes maestros y, lo que la ENAH perdió, lo ganó la Escuela de Antropología Social de la Universidad lberoamericana, lo que más tarde sería el Departamento de Antropología y su doctorado, encabezados por Palerm y Arturo Warman (TéllezGirón \& Vázquez, 2013).

¿Realmente es un dilema tajante el ser o no internacionales? El problema a mi juicio está mal planteado. No se trata de decidir entre una u otra orientaciones, sino el reto es hacerles combinables de la mejor forma posible. Para empezar, las buenas y malas ideas producidas en otros contextos seguirán siendo trasplantadas a México por brokers, intelectuales (caso de la época en que era un puñado la gente que salía al extranjero), pero más aún por sus intérpretes (y cultivadores) locales. Hoy cualquier investigador con estudios suficientes, está en capacidad de hacerlo y no solo de imitar esas ideas. Qué tan correcta o no sea su interpretación, es materia de otra discusión. La globalidad digital ha hecho de este intercambio masivo de información un asunto acuciante, dada su vasta magnitud. Este puede ser un factor que haga ver el problema como crucial. Siempre uno va a padecer la sensación de quedarse atrás, olvidándose de la importancia del estar aquí. Pero aparte de ese problema de actualización, es claro que la antropología siempre ha sido una disciplina universalista, con sentido metropolitano. Basta ver toda la literatura que el viejo Museo Nacional reunió por intercambio durante años, para darse cuenta de que las antropologías mundiales de los imperios siempre han estado ahí para su lectura $y$, que a nuestro modo, seguimos apelando a tal literatura, aunque a veces el encierro nacional aparente ser una jaula de oro comodísima.

Más, tan grave resulta el ignorar a propósito el conocimiento generado afuera, como el suponer que toda la producción nacional es mediocre. Por desgracia (y de seguro por su costo), el INAH dejó de publicar sus Anales, que entre otras cosas daba cuenta de la producción antropológica del momento. Hoy esa labor divulgativa debería recaer en los dos colegios profesionales, el Colegio de Etnólogos y Antropólogos sociales A.C. (CEAS) ya mencionado y, la Sociedad Mexicana de Antropología, pero ésta yace tan aletargada que no publica siquiera las memorias de sus congresos. EI CEAS ha optado en cambio por el formato de revista, informando en su boletín solo de eventos venideros. Además hay que decirlo con todas sus letras, a causa de los conflictos citados, la antropología mexicana quedó fracturada como comunidad, fractura que sigue las líneas institucionales y a los dos colegios profesionales opuestos. Solo hasta fechas recientes, en los primeros dos congresos del CEAS, se pudo apreciar una asistencia creciente de investigadores del INAH, pero no es suficiente. Tampoco es conveniente para el interés general de la profesión que se rebaje a unos como marginales y se resalte a otros como mainliners o mainstreamers, serían la creme de la creme antropológica, lo que he llamado la elite académica, casi toda proveniente de la Universidad Iberoamericana (UIA). La contribución escrita por los investigadores del INAH es tremenda-ella sola basta para llenar varias revistas al año, lo que ocurre de hecho-, lo mismo que en el CIESAS y, no hay universidad ni colegio del que no se diga lo mismo. 
Sea porque el Sistema Nacional de Investigadores (SNI) ha estimulado esta práctica o, porque el mercado laboral es tan reducido que la exigencia de publicar es obligada para hacerse de un lugar en él, el punto es que no puede simularse menosprecio alguno. Si no fuera por toda esa variada literatura especializada, estaríamos todos en serios problemas. Además, como ya dije, así se hace normalmente la antropología, con esa labor cotidiana y paciente de mucha gente. Es de lamentarse entonces que no hagamos lo que los historiadores: en el Boletín del Comité Mexicano de Ciencias Históricas consignan todas las publicaciones recientes de su disciplina. Usualmente hallamos en él eventos, presentaciones de libros, convocatorias y en su última entrega digital un enlace al Catálogo de Tesis de Historia 1931-2011.

Esta última mención me lleva al asunto de la literatura gris de las tesis, que rara vez son publicadas. La labor del INAH (y en menor escala en los certámenes del CIESAS Golfo y el Colegio de Michoacán) para premiarlas año con año, resulta meritoria porque visibiliza esa literatura a todos los niveles: licenciatura, maestría y doctorado, aún como nuevas publicaciones también. Pero asimismo resalta la carencia de catálogos generales. Esta fue una labor que se inició en el INAH (Montemayor 1971), se mantuvo en la ENAH (Ávila et al., 1988), siguió con una pretensión latinoamericana en el CIESAS Golfo (García Valencia, 1989) y luego se extinguió, hasta que la UIA la revivió para exhibir su propia producción (Pérez \& Arce, 2012:500515); finalmente el CIESAS de Occidente usó algunas contribuciones de sus alumnos para celebrarse, pero que no conforman ningún catálogo (Villarreal \& Preciado, 2012). A pesar de que en las reuniones de la Red Mexicana de Instituciones de Formación de Antropólogos (Red MIFA) se ha mencionado esta carencia, no tenemos un catálogo nacional de tesis de antropología en todas sus especializaciones profesionales y niveles. Hacerlo no es mera cuestión de elaborar bases de datos y hacer biblioestadísticas. Entraña un asunto mayor. Como en CONACYT lo saben, es un indicador de la eficiencia de los programas educativos vigentes. Pero hay mucho más implicado, según sostengo es una expresión del interés de conocimiento real de los nuevos profesionales. En muchos posgrados, por ejemplo, hay también una marcada tendencia a seguir y repetir conocimientos convencionales, que suelen ser los de moda. En ese sentido he podido apreciar cómo los comités de premiación optan por lo convencional y menosprecian la innovación presente en las tesis más singulares y novedosas, que son precisamente las desechadas.

¿Es que la "ciencia normal" no es pertinente? O por el contrario, ¿es que nuestra élite ha producido tal revolución científica estilo "kuhniano", como para dejarlo todo y adoptar su nuevo sentido de pensar la realidad? Que yo sepa nada así ha ocurrido y, la actividad normal es persistente, acumulativa y necesaria en varios sentidos. Por eso es que toda investigación empieza por una revisión de la literatura previa, de toda índole. Es innegable, sin embargo, que algunos investigadores destacados sí han generado programas de investigación que han atraído a otros a imitarlos. Con todo, son programas muy simples y para consumo doméstico. Puede ser que los genios brillen por su ausencia, pero me inclino por apostarle a las masas críticas de investigadores cooperantes. Además, mucha de la trascendencia latinoamericana de pensadores mexicanos vino de la antropología gubernamental -quiero decir de los intelectuales políticos en nuestra profesión- y, del impacto que provocó 
el Fondo de Cultura Económica en los países hispanohablantes en momentos difíciles, políticamente hablando. Tal parece que se conjugaron varios factores a su favor. Como quiera que haya sido, se leyeron e influyeron en Latinoamérica y España y, hubo casos en que se les tradujo a otros idiomas. Conviene pues no jactarse de nuestra internacionalización per se. Esto me lleva a un asunto planteado por Poblocki (2009), en respuesta al ideal de una "comunidad trasnacional de antropólogos", de Lins Ribeiro y Escobar (2006). Poblocki ha salido en defensa del supuestamente provinciano conocimiento antropológico nacional, haciendo especial referencia a la importancia de la historia económica y etnología polaca y, húngara. Aparte del idioma, en las antropologías dominantes se les ignora desde el (des) uso de la lengua vernácula. Muestra entonces las jerarquías del conocimiento antropológico, según la región y según la falta de interés recíproco, desde los nichos superpuestos en el mercado global de conocimiento. No opera en ellos ninguna heteroglosia, es pura ignorancia asimétrica. Con privilegiadas excepciones, se reconoce que el paradigma nacionalista también ha aportado conocimiento. Es el caso de Immanuel Wallerstein (1979 [1974]), quién leyó al parejo a Franz Fanon junto con los historiadores polacos. Se infiere pues que su teorización es producto de logros locales y logros metropolitanos, del conocimiento comprensivo y crítico. Ese es el camino indicado. Si hay que entrar al escaparate internacional, la antropología mexicana conjuntada debería fijar una agenda con sus intereses de conocimiento y, si es preciso, negociarlos afuera. Así como debemos esforzarnos por comprender los contextos e ideas ajenos, es posible que busquemos los nichos indicados para comunicarlos lo mejor posible.

\section{¿Comunidades ideales, reales o virtuales?}

El caso del indigenismo es digno de mención en este contexto. En sus días de auge, no se habló nunca de una "comunidad transnacional", pero su resonancia latinoamericana lo recuerda. Ante todo, fue una creación de la antropología gubernamental que, en sus mejores momentos, influyó en procesos similares en varios países que imitaron no solo la política social implicada, sino varias de las ideas que la inspiraban. Por supuesto, que es pertinente distinguir entre el indigenismo del campo interamericano (o sea, el propagado por el Instituto Indigenista Interamericano, que muy pronto fue controlado por el Departamento de Estado americano) y el campo propiamente mexicano (esto es, del Departamento de Asuntos Indígenas, y luego del Instituto Nacional Indigenista-INI). Y es que el primero sufrió inconsistencias (ambivalencias las llaman Giraudo \& Martín-Sánchez, 2011), que el segundo pudo enfrentar con ajustes internos y cierta dosis de soberanía nacional. Del conflicto de 1971 -en que los antropólogos sociales jóvenes cuestionaron su cometido aplicado y único-, surgió un INI renovado, hasta que en 2003 ya no pudo regenerarse. Es significativo que desde entonces, se crearon instituciones multiculturales inspiradas en ideas foráneas, en especial provenientes de Canadá y la OIT (Vázquez, 2010).

¿Cómo fue que el INI pudo sobrevivir cinco décadas, cuando las instituciones multiculturales han entrado en decadencia en una década? Claro, resulta obvio mencionar el sostén gubernamental, que fue también el que, al menguar, dio al traste con toda la institución. Pero hablo aquí de las ideas que forjaron su espíritu de cuerpo, tan caro al pensamiento de Gonzalo Aguirre Beltrán (y es posible que sea de nuevo la impronta de Alfonso Caso). 
Un hecho poco sopesado, es que él mismo procuraba adaptarse hasta cierto punto a los cambios de ideas. A ello atribuyo el que haya hecho el último recuento bibliográfico del campo indigenista mexicano, mediante un repaso de todas las publicaciones con el tema indígena hasta 1975 (Aguirre, 1978). Pero también hizo otra cosa loable, estimuló y mantuvo la Colección de Antropología Social de cerca de cien títulos donde aparecieron tanto investigadores nacionales como extranjeros. A fines de los años ochenta, el INI (apoyado por el Consejo Nacional para la Cultura y las Artes) reimprimió la colección, ahora renombrada como Presencias. Pero algo estaba ya fallando en el mecanismo de reproducción de ideas indigenistas, porque fueron desapareciendo las contribuciones originales. Es muy probable que la crisis profesional ocurrida en 1971, llevara a resquebrajar lo que era la comunidad de indigenistas, que debían al INI una entrega incondicional. El espíritu de cuerpo de la época de oro dejó de tener sentido a la profesión. Vino con ello la fragmentación, como una diversificación de temáticas de estudio más y más de interés académico. Solo el Programa Universitario México Nación Cultural de la UNAM, ha conseguido unificar las ideas multiculturales en torno a su colección "La pluralidad cultural de México", con veinticinco entregas.

El conflicto por la orientación general de la antropología social (García Mora \& Medina, 1983,1986) fue, en general, apreciado positivamente por sus practicantes porque de una parte favoreció la pluralidad de enfoques y temas de estudio (antes los temas eran indigenistas o etnológicos únicamente) y, por otro lado, indujo a generar instituciones más y más académicas. Todavía en sus inicios (1973-1974), el CISINAH bajo la dirección de Ángel Palerm insistía en atender "los grandes problemas nacionales", una frase aplicada por uno de los iniciadores de la antropología social en México, Andrés Molina Enríquez y, que desapareció del lenguaje profesional durante el proceso de academización que sobrevino luego de 1971. Es llamativo entonces, que los organizadores del III Congreso Mexicano de Antropología Social y Etnología (a celebrarse en septiembre de 2014) hayan vuelto a usar esas palabras, urgidos por la multiplicidad de problemas del país. También hablan de una presunta "comunidad antropológica mexicana" que, aparte de la docencia, también comparte la preocupación por esos problemas. Ya que no existe ningún consenso sobre cuáles son esos problemas, queda claro que tal comunidad ha de ser construida por algo más que congresos que momentáneamente crean una comunidad virtual, pues ello exige mayor institucionalidad. No deja de ser preocupante que mientras el CEAS busca abrirse a todos, los investigadores del INAH celebren aparte su VIII Congreso. Es innegable que estas celebraciones aún son solo para miembros, pero se revela que no hay un sentimiento comunitario recíproco, ni siquiera si este es virtual.

En realidad, no hay consenso tampoco respecto del rumbo de la antropología y da la impresión, de que no está en nuestras manos fijarlo. Los dos rumbos iniciales se mantienen, a condición de abstraer cuál será el futuro de las generaciones estudiantiles arrojadas por esa treintena de escuelas, facultades, institutos, colegios y centros de investigación. La ruptura ocurrida entre los antropólogos críticos y tradicionales, marcó esos dos caminos. En cierto modo, la distinción entre la antropología gubernamental y la antropología académica, viene de antes y coincide con la muerte de Alfonso Caso. 
Así ocurrió que Ángel Palerm se erigió como provocador de instituciones académicas (Vázquez, 1998 y 1999) mientras que Guillermo Bonfil y Arturo Warman se adentraron en las instituciones gubernamentales, reformándolas en distintos sentidos, algunos de ellos muy controvertidos. Para haber sido funcionarios públicos, las credenciales académicas de ambos eran impecables. Y fuera de México, tuvieron fuerte resonancia. Como intelectuales políticos, claro está que veían con preocupación el proceso de separación de la antropología de los deberes de Estado. No obstante, como segundo director del CISINAH y en plena transición al CIESAS, es paradójico que Guillermo Bonfil haya influido tanto en volver a la temática indígena (que no indigenista) y que ésta sea hoy uno de los emblemas de la institución. Obvio, ya había investigadores dedicados a ello, no fue un giro radical.

¿Hubo un proceso de conocimiento análogo desde la antropología académica hacia la gubernamental? Hasta aquí he mostrado que ambos campos se entrelazan en varios puntos, pero en otros se disgregan de plano. El tema del patrimonio cultural y su administración es todavía exclusivo del INAH y, en ese sentido, Bonfil cumplió funciones de mediación a fin de introducir reformas (Vázquez, 2003:334). Con Warman la antropología gubernamental llegó a un punto culminante y sus funciones de mediador fueron menos claras, aunque atrajo a muchos profesionales al INI y otras instituciones (Vázquez, 2014). Sin embargo, personajes como ellos desaparecieron y con ello sobrevino la carencia, si no de intermediarios, sí de interlocutores en dominios claves de interés para toda la profesión. A cambio, la carrera académica se convirtió en básica ("ciencia básica"), pero por entero reducida a los méritos conseguidos en las trayectorias individuales.
Si esos méritos son o no vitales para el país, eso lo deciden otros académicos que se reconocen en el espejo. Por lo tanto, es difícil responder a la cuestión del conocimiento puro con impacto conductual significativo. Si lo hay en calidad de consultoría, no es de los alcances que se tuvo en otras épocas en que la antropología tenía una presencia pública destacada y, que no se trataba solo de libros, artículos y ponencias de interés para la propia academia.

En el presente, esta disgregación individual implica un doble efecto perverso. Por un lado, propicia la ausencia correlativa del espíritu de cuerpo que hubo en el INI y que en el INAH persiste con rasgos anacrónicos. La fundamentación de una comunidad profesional efectiva, que rebase las constancias de asistencia a congresos solo para puntualizarlas, es un reto que valdría plantear a modo de interés de supervivencia de la profesión en su conjunto. Por otro lado, mucho del éxito académico de lo que he llamado la élite antropológica, está basado en una especie de espíritu corporativo restringido, sustentado en su origen profesional común y una suerte de ideología armónica compartida a propósito de su fundador. En su origen, esta élite fue un avance, pero ya da muestras de obstaculizar a toda la profesión, cuyo objetivo central no puede ser la de acumular capital cultural en la carrera de cada uno. El disimulado escándalo de abuso en los juicios de pares del SNI, involucra precisamente, a miembros de esta élite.

\section{Conclusiones}

El siglo de surgimiento profesional de la antropología mexicana ha sido multifacético y muy rico en su creatividad interna, pero está encarando problemas que conviene discutir seriamente. 
La oposición tajante, en sus inicios, entre una antropología gubernamental y una académica va a mantenerse porque involucra a dos instituciones asaz constituidas, amén de un universo variado de universidades y colegios, no todos con funciones de investigación, pero sí de docencia. Desde luego que esas funciones seguirán en vigor. Pero lo que aquí importa, son los miembros de esas instituciones y cómo interactúen. En la perspectiva provisional que ofrezco, percibo puntos de intersección que pueden ser de colaboración y aproximación. Las instituciones, como han mostrado la Red MIFA y la Red Mexicana de Arqueología (RMA), no son motivo para mantenerse fragmentados, sino que pueden y deben verse como nichos donde están activos los profesionales.

Otro desafío en perspectiva, es el mantenerse en el horizonte nacional o perseguir el internacional. En realidad, no se trata de materia de elección sino una desiderata. La "solución óptima" dirían algunos. El punto es que no hemos sabido apreciar el valor de que estamos aquí, en un país motivo de interés internacional por las más diversas razones. Pero aún si nos restringimos a lo estrictamente antropológico, es de destacarse que ese interés externo requiere de nuestra experticia. Que académicos extranjeros se comporten como si los logros internos fueran despreciables, no debiera importarnos tanto, ya que también hay investigadores mexicanos que actúan igual con los aportes externos. En realidad lo que importa, es encontrar los puntos de confluencia y comunicación adecuados, sea participando en colaboraciones o, de plano, pensando en llevar a nuestras revistas a otro nivel que el reconocimiento de CONACYT. Por último, está el siempre complicado asunto de superar lo mejor posible los conflictos del pasado y buscar la cooperación a su pesar.
Mientras algunas generaciones antropológicas de uno y otro bando, tenían plena conciencia de los diferendos y agravios, las actuales generaciones los van dejando en los anaqueles de la historia profesional. Quizás no haya que olvidarlos del todo, porque también se aprende de ellos, pero tampoco darles un papel central en las interacciones profesionales. Son éstas las que importan, no lo mal que nos hemos llevado hasta hoy. En todo caso, esas rupturas son un constante recordatorio de que pueden volver a ocurrir en el futuro. 


\section{Referencias bibliográficas}

Aguirre Beltrán, G. (1978). "La antropología social". En Las humanidades en México 1950-1975, México: UNAM, pp.545-644.

Ávila, A., Martínez, F., Quintanar B., \& Tello, M. (1988). Las tesis de la ENAH. Ensayo de sistematización, México: ENAH-INAH.

CEAS (2013). Antropología y prácticas profesionales diversas, Boletín del Colegio de Etnólogos y Antropólogos Sociales, A.C.

Escalante, Y. (ed.) (2002), La experiencia del peritaje antropológico, México: Instituto Nacional Indigenista.

Faulhaber, P. (2011). "I Instituto de Antropologia Social (EUA, Brasil e México): Um Artefato da Resposta Antropológica Ao “Esforco de Guerra”. Mana, 17 (1):9-39. García Mora, C. (ed.), (1987-1988) La antropología en México. Panorama histórico, 15 volúmenes, INAH.

García Mora, C. \& Medina, A. (eds.) (1983-1986) La quiebra política de la antropología social en México, 2 volúmenes, UNAM

García Valencia, E.H. (1989). Catálogo Latinoamericano de Tesis de Antropología. México, volumen 1, CIESAS Golfo

Giglia, Á., Garma C. \& de Teresa, A.P. (eds.) (2007) ¿Adónde va la antropología?, UAM.

Giraudo, L. \& Sánchez, J.M. (eds.) (2011) La ambivalente historia del indigenismo. Campo interamericano y trayectorias nacionales 1940-1970, Instituto de Estudios Peruanos.

Krotz, E. \& de Teresa, A. P. (eds.) (2012) Antropología de la antropología mexicana. Instituciones y programas de formación, I y II, México: UAM-Red MIFA-Juan Pablos Editor.

Lins Ribeiro, G. \& Escobar, A. (eds.) (2006). World Anthropologies. Disciplinary Transformations within Systems of Power, Berg.

Montemayor, F. (1971). 28 Años de Antropología. Tesis de la Escuela Nacional de Antropología e Historia, México: INAH.

Poblocki, K. (2009). "Whiter Anthropology without Nation-state? Interdisciplinary, World Anthropologies and Commoditization of Knowledge". Critique of Anthropology, 29(2):225-252.
Rustch, M. (2007). Entre el campo y el gabinete. Nacionales y extranjeros en la profesionalización de la antropología mexicana (1877-1929), México: INAH-UNAM.

Téllez-Girón, R. \& Vázquez León, L. (eds.) (2013). Palerm en sus propias palabras. Las entrevistas al Dr. Ángel Palerm Vich realizadas por Marisol Alonso en 1979, México: CIESAS-BUAP.

Vázquez León, L. (2002). "Quo Vadis Anthropologia Socialis?". En Guillermo de la Peña \& Vázquez L.(eds.). La antropología sociocultural en el México del milenio. Búsquedas, encuentros y transiciones, México: Fondo de Cultura Económica, pp.50-104.

(1998). "Ángel Palerm y la institucionalización de la antropología social en México", Alteridades, 8 (15): 167-184.

(1999). "La metamorfosis de la antropología crítica: conocimiento y poder en México", Estudios del Hombre 8:95-118.

(2003). El Leviatán Arqueológico.

Antropología de una tradición científica en México, México: CIESAS-Miguel Ángel Porrúa.

(2010). "El indigenismo ha muerto. ¿Viva la gestión étnica empresarial?", Multitud y distopía. Ensayos sobre la nueva condición étnica en Michoacán, México: UNAM-PUMC, pp.181-219.

(2014). Historia de la etnología. La antropología sociocultural mexicana, Primer Círculo Editorial (en prensa).

Villalobos Nájera, H. \& Coronado Ramírez, R. (2003). La Escuela Nacional de Antropología e Historia, un proyecto académico-político, 1938-1981,Tesis de licenciatura en antropología social.

Villarreal, M. \& Preciado, J. (eds.) (2012). Dilemas, debates y perspectivas. Ciencias sociales y reflexividad, México: CIESAS de Occidente.

Wallerstein, I. (1979). El moderno sistema mundial. La agricultura capitalista y los orígenes de la economíamundo europea en el siglo XVI, México: Siglo XXI Editores. 